\title{
Impact of age-associated increase in 2'-O-methylation of miRNAs on aging and neurodegeneration in Drosophila
}

\author{
Masashi Abe, ${ }^{1}$ Ammar Naqvi, ${ }^{2}$ Gert-Jan Hendriks, ${ }^{1,3}$ Virzhiniya Feltzin, ${ }^{1}$ Yongqing Zhu, ${ }^{1}$ \\ Andrey Grigoriev, ${ }^{2,4}$ and Nancy M. Bonini ${ }^{1,4}$ \\ ${ }^{1}$ Department of Biology, University of Pennsylvania, Philadelphia, Pennsylvania 19104, USA; ${ }^{2}$ Department of Biology, Center for \\ Computational and Integrative Biology, Rutgers University, Camden, New Jersey 08102, USA
}

\begin{abstract}
MicroRNAs (miRNAs) are 20- to 24 -nucleotide (nt) small RNAs that impact a variety of biological processes, from development to age-associated events. To study the role of miRNAs in aging, studies have profiled the levels of miRNAs with time. However, evidence suggests that miRNAs show heterogeneity in length and sequence in different biological contexts. Here, by examining the expression pattern of miRNAs by Northern blot analysis, we found that Drosophila miRNAs show distinct isoform pattern changes with age. Surprisingly, an increase of some miRNAs reflects increased 2'-O-methylation of select isoforms. Small RNA deep sequencing revealed a global increase of miRNAs loaded into Ago2, but not into Ago1, with age. Our data suggest increased loading of miRNAs into Ago2, but not Ago1, with age, indicating a mechanism for differential loading of miRNAs with age between Ago1 and Ago2. Mutations in Hen1 and Ago2, which lack 2'-O-methylation of miRNAs, result in accelerated neurodegeneration and shorter life span, suggesting a potential impact of the ageassociated increase of $2^{\prime}$ - $O$-methylation of small RNAs on age-associated processes. Our study highlights that miRNA 2'-O-methylation at the $3^{\prime}$ end is modulated by differential partitioning of miRNAs between Ago1 and Ago2 with age and that this process, along with other functions of Ago2, might impact age-associated events in Drosophila.
\end{abstract}

[Keywords: miRNA; 2'-O-methylation; miRNA sorting; aging; neurodegeneration]

Supplemental material is available for this article.

Received August 29, 2013; revised version accepted December 3, 2013.

MicroRNAs (miRNAs) are 20- to 24-nucleotide (nt) small RNAs that regulate gene expression post-transcriptionally through translational repression and/or mRNA cleavage. Starting from the discovery of the first miRNA lin- 4 in Caenorhabditis elegans, hundreds of miRNAs have now been identified in various species. miRNAs were classically studied for their role in developmental timing (Lee et al. 1993; Reinhart et al. 2000; Bartel 2004). By now, functional analyses have identified some miRNAs, such as lin-4 in C. elegans (Boehm and Slack 2005; Kenyon 2010; Smith-Vikos and Slack 2012) and miR-34 in Drosophila (Liu et al. 2012), as miRNAs with critical roles in organismal and brain aging, respectively. Although most studies have focused on changes in the abundance of miRNAs with age (Ibanez-Ventoso et al. 2006; de Lencastre et al. 2010; Kato et al. 2011), evidence

\footnotetext{
${ }^{3}$ Present address: Friedrich Miescher Institute for Biomedical Research, Maulbeerstrasse 66, 4058 Basel, Switzerland

${ }^{4}$ Corresponding authors

E-mail nbonini@sas.upenn.edu

E-mail agrigoriev@camden.rutgers.edu

Article is online at http://www.genesdev.org/cgi/doi/10.1101/gad.226654.113.
}

suggests that miRNAs also show heterogeneity in length and sequence in different cell types and biological contexts (Burroughs et al. 2010; Marti et al. 2010; Li et al. 2012; Westholm et al. 2012; Llorens et al. 2013). Such heterogeneity is mediated by imprecise Drosha and Dicer cleavages (Calabrese et al. 2007; Azuma-Mukai et al. 2008; Wyman et al. 2011), 3' end adenylation/ uridylation (Ruby et al. 2006; Landgraf et al. 2007; Burroughs et al. 2010; Wyman et al. 2011), and RNAediting events (Kawahara et al. 2007; Nishikura 2010; Alon et al. 2012; Ekdahl et al. 2012). Importantly, effects of this heterogeneity on miRNA target silencing are also reported (Azuma-Mukai et al. 2008; Seitz et al. 2008; Fukunaga et al. 2012; Lee and Doudna 2012), suggesting a functional impact of regulating miRNA heterogeneity in animals. Our study on the role of miR-34 in aging and age-

(C) 2014 Abe et al. This article is distributed exclusively by Cold Spring Harbor Laboratory Press for the first six months after the full-issue publication date (see http://genesdev.cshlp.org/site/misc/terms.xhtml). After six months, it is available under a Creative Commons License (Attribution-NonCommercial 3.0 Unported), as described at http:// creativecommons.org/licenses/by-nc/3.0/. 
associated neurodegeneration in Drosophila revealed an intriguing pattern of miR-34 isoforms: Although multiplelength isoforms of miR-34 are generated, only the short isoform accumulates with age (Liu et al. 2012). Furthermore, the generation of isoforms of miR-34 requires $3^{\prime}$ end trimming by a novel 3 '-to-5' exonuclease, Nibbler (Nbr) (Han et al. 2011; Liu et al. 2011), highlighting the potential importance of regulation of miRNA length in age-associated processes.

In addition to length and sequence heterogeneity, the $2^{\prime}-\mathrm{OH}$ of the $3^{\prime}$ terminal ribose of miRNAs can be modified by $2^{\prime}$-O-methylation (Zhao et al. 2012a). In plants, this modification occurs on nearly all miRNAs and siRNAs (Yu et al. 2005; Zhao et al. 2012a,b) and protects the small RNAs from HESO1-mediated uridylation and degradation (Li et al. 2005; Yu et al. 2005; Ren et al. 2012; Zhao et al. 2012b). In Drosophila, most miRNAs are loaded into Agol and remain unmodified (Hutvagner et al. 2001; Okamura et al. 2004; Vagin et al. 2006). However, a subset of miRNAs are found to be 2 ' $-O$ methylated (Forstemann et al. 2007; Horwich et al. 2007; Ghildiyal et al. 2008; Czech et al. 2009; Okamura et al. 2009). Importantly, this modification is also protective in animals: Loss of 2'-O-methylation of small RNAs leads to destabilization as well as tailing and trimming of the small RNAs (Kurth and Mochizuki 2009; Ameres et al. 2010; Kamminga et al. 2010).

In Drosophila, 2'-O-methylation of small RNAs is associated with loading of the miRNAs into different Ago complexes: While most miRNAs are loaded into Ago1 (Ago1-RISC) and remain unmodified, those loaded into Ago2 (Ago2-RISC) are 2'-O-methylated (Czech et al. 2009; Okamura et al. 2009; Ghildiyal et al. 2010). The miRNA/miRNA* duplex structure and 5' nucleotide preference are two suggested mechanisms by which miRNAs are directed into the two distinct Ago complexes (Forstemann et al. 2007; Tomari et al. 2007; Okamura et al. 2009; Ghildiyal et al. 2010). miRNAs loaded into Ago2 are also active in translational silencing of the target genes, like miRNAs loaded into Ago1, but by a potentially different mechanism and with different silencing efficiency (Czech et al. 2009; Iwasaki et al. 2009; Okamura et al. 2009). However, despite the discovery of functional Ago2-loaded and 2'-O-methylated miRNAs in Drosophila, whether such loading of miRNAs to Ago2 is biologically regulated or biologically important in vivo is not yet clear.

Here, we pursued the study of several Nbr-dependent miRNAs that, like miR-34, show multiple isoforms. Examination of changes in their isoform patterns with age unexpectedly revealed a diversity of patterns. The age-associated increase of some Drosophila miRNAs reflected increased 2'-O-methylation of select isoforms. Associated with this increase, we found increased loading of specific miRNA isoforms into Ago2, but not Ago1, with age. Furthermore, the lack of 2'-O-methylation by Hen 1 and Ago2 mutations resulted in reduced life span and brain degeneration, raising the possibility that the increased protection of small RNAs with age may impact age-associated events.

\section{Results}

Distinct age-associated isoform patterns of Nbr-trimmed miRNAs

Drosophila miR-34-5p, which is a target of Nbr-dependent $3^{\prime}$ end trimming (Han et al. 2011; Liu et al. 2011), shows an increase in the short isoform with age (Fig. 1A,B; Liu et al. 2012). This observation led us to examine the age-associated pattern of other Nbr-trimmed miRNAs. We focused on several miRNAs that could be readily detected by Northern analysis. Northern blots of these miRNAs at $3 \mathrm{~d}$ and $30 \mathrm{~d}$ in heads revealed intriguing changes in isoform patterns. One Nbr-trimmed miRNA, miR-317-3p, increased with age like miR-34-5p (Fig. 1A,B). The increase in both of these miRNAs reflected an increase in their short isoforms with age. In contrast, although both miR-305-5p and miR-263a-5p increased in total amount with age, their isoform patterns were opposite: These miRNAs showed an increase in the longer isoforms with age (Fig. 1C,D). miR-11-3p showed a single isoform by Northern and increased by $30 \mathrm{~d}$ (Fig. $1 \mathrm{E}, \mathrm{F})$. These observations raised the possibility that multiple mechanisms are used to generate distinct miRNA isoform patterns with age.

\section{Age-associated increase in 2'-O-methylation} of Nbr-trimmed miRNAs

One mechanism to explain an increase in long isoforms with age could be an increased protection of these specific isoforms with age. Almost all plant miRNAs and siRNAs (Li et al. 2005; Yu et al. 2005; Ren et al. 2012; Zhao et al. $2012 \mathrm{~b}$ ) and animal siRNAs and piRNAs are 2'-O-methylated (Horwich et al. 2007; Kirino and Mourelatos $2007 \mathrm{a}, \mathrm{b}, \mathrm{c})$. Recent studies also suggest that a subset of Drosophila miRNAs are 2'-O-methylated (Forstemann et al. 2007; Horwich et al. 2007; Czech et al. 2009; Okamura et al. 2009; Ghildiyal et al. 2010). Importantly, 2 '-O-methylation of animal small RNAs is also protective such that loss of 2'-O-methylation leads to their destabilization (Ameres et al. 2010; Kamminga et al. 2010). Therefore, we hypothesized that the increase of the long isoforms of miR-305-5p, miR-263a-5p, and miR11-3p may result from increased protection at the $3^{\prime}$ end of specific isoforms by 2 '-O-methylation. To address this, we performed oxidation $/ \beta$-elimination assays on total RNA from 3-d and 30-d wild-type heads and bodies. If the $3^{\prime}$ end ribose of small RNAs is protected by $2^{\prime}-O$ methylation, as for piRNAs and siRNAs, those small RNAs cannot react with sodium periodate in the oxidation/ $\beta$-elimination assay and will not decrease in size. However, if the $3^{\prime}$ end ribose is unmodified, they can react, will be $\beta$-eliminated, and will shift down in length (Horwich et al. 2007). Therefore, a change in the mobility of the small RNAs by Northern indicates the presence or absence of a protective modification at the $3^{\prime}$ end. We performed this assay and found that miR-34-5p shifted down in size and thus is not protected at the $3^{\prime}$ end (Fig. 2A, left panel). In contrast, miR-305-5p, miR-263a-5p, and miR-11-3p showed an increase in protection of the long 
A

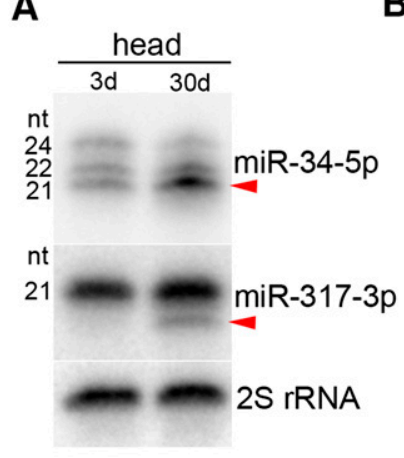

C
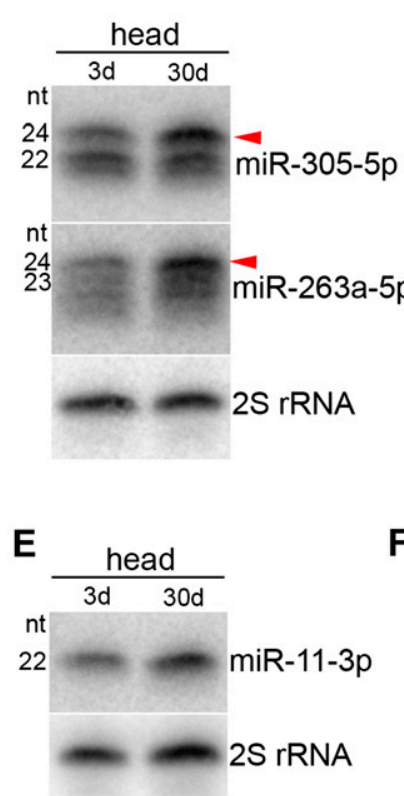
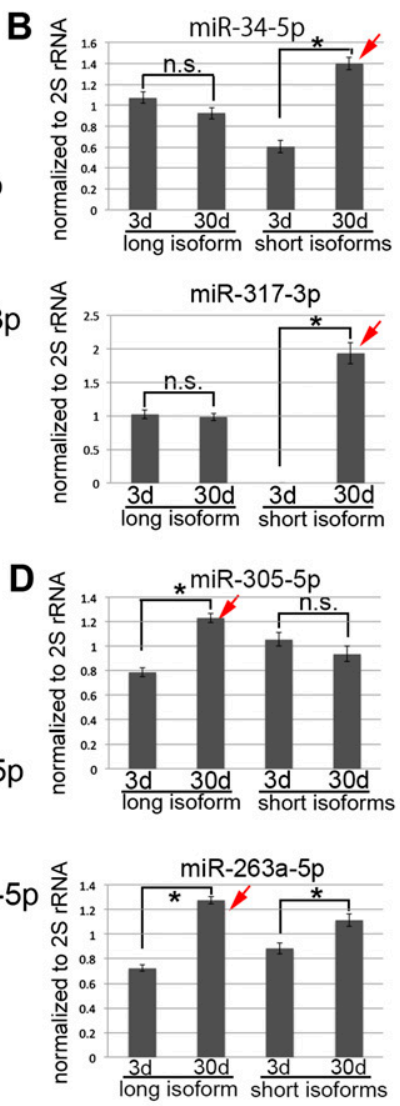
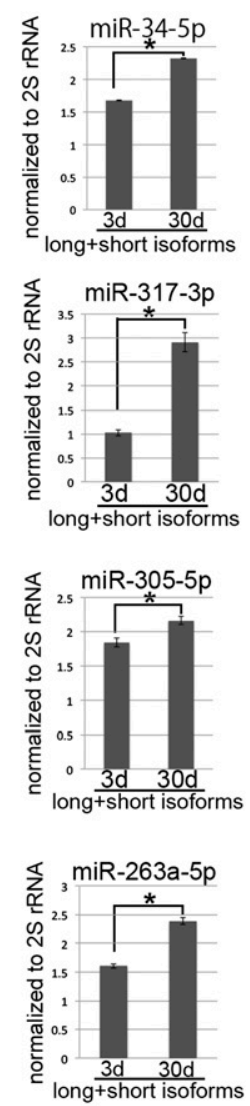

Figure 1. Nbr-dependent miRNAs show distinct isoform patterns with age. Northern blots of different Nbr-dependent miRNAs with age. $(A, B$, left panel) miR-34-5p and miR-317-3p showed accumulation of short isoforms with age. $(B$, right panel) Both miR-34-5p and miR-317-3p also increased in total amount with age. (C,D, left panel) miR-305-5p and miR-263a-5p showed accumulation of long isoforms with age. $(D$, right panel) Both miR-305-5p and miR-263a-5p increased in total amount with age. $(E, F)$ miR-11-3p, a singleform miRNA by Northern, accumulated with age. $(B, D$, left panels, $F)$ Quantification of the different isoforms of each miRNA. (Right panels) Quantification of the total amount of each miRNA with age. Red arrowheads and arrows indicate the isoforms that increased with age. Mean \pm SD. $n=3$; (*) $P<0.05$ (Student's $t$-test).

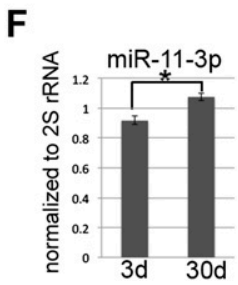

isoforms with age (Fig. 2A, right panel, arrows). Quantification of the ratio of protected to unprotected isoforms of miR-305-5p, miR-263a-5p, and miR-11-3p showed an increase in the ratio of protected to unprotected isoforms with age. If the increase of the protected isoforms simply reflected an increase of the overall level of these miRNAs, the ratio of protected to unprotected isoforms after oxidation $/ \beta$-elimination would not change. However, the ratio increased for these three miRNAs (Fig. 2B), indicating a mechanism to increase the protection of the long isoforms of these miRNAs with age.

We next determined whether the protection of specific miRNA isoforms is due to 2'-O-methylation at the $3^{\prime}$ end. 2'-O-methylation of small RNAs depends on the methyltransferase Hen 1. In addition, 2'-O-methylation of small RNAs requires loading into Ago2: Loss of Ago2 and Ago2-loading machinery (Dcr2 and R2D2) leads to loss of modification (Horwich et al. 2007). Therefore, to confirm that the miRNAs were 2 '-O-methylated and loaded into Ago2, we tested the effect of loss of Hen1 and Ago2 on the pattern of miR-305-5p, miR-263a-5p, and miR-11-3p with age. Hen $1^{f 00810}$ and $A g O 2^{B L 16608}$ mutant flies were aged to
$3 \mathrm{~d}$ or $30 \mathrm{~d}$, RNA was isolated, and oxidation/ $\beta$-elimination was performed. This revealed that miR-305-5p, miR263a-5p, and miR-11-3p were no longer protected but rather depended on Hen1 and Ago2 for protection at both $3 \mathrm{~d}$ and $30 \mathrm{~d}$ (Fig. 3, arrowheads). This finding indicates that the increase of the long isoforms of these miRNAs is dependent on Hen 1 and thus is due to 2'-O-methylation at the $3^{\prime}$ end. These data also indicate that these miRNA isoforms are loaded into Ago2 for 2'-O-methylation. We note that miR-317-3p is exceptional in that it showed protection of the long isoform from oxidation/ $\beta$-elimination in both young and old flies (see Fig. 2A, arrowheads); however, to our surprise, protection persisted even after the loss of Hen1 and Ago2 (Fig. 3, arrowheads). This suggests that miR-317-3p is protected in a manner independent of Hen1 and Ago2 function.

An age-associated increase in Ago2 loading of 2'-Omethylated isoforms of miRNAs

In Drosophila, while most miRNAs are loaded into Agol and thus are unmodified, a subset of miRNAs has been 


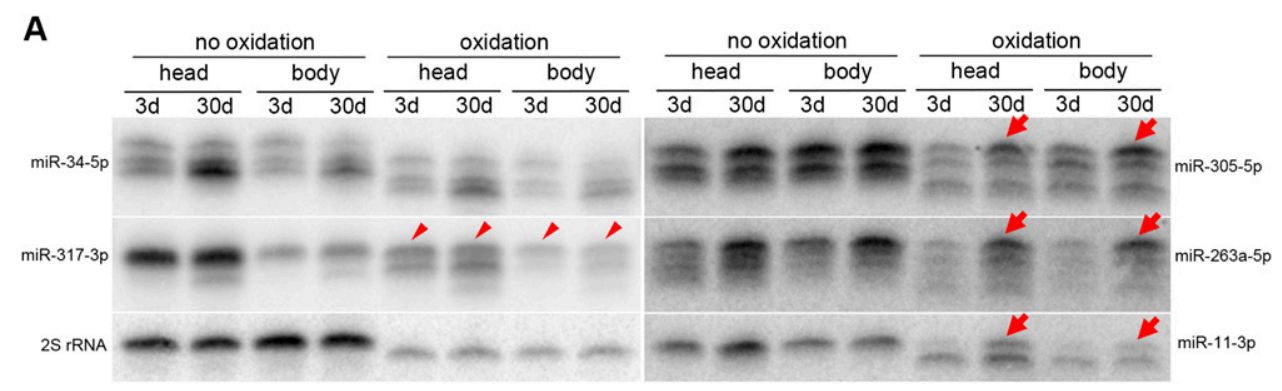

\section{B}

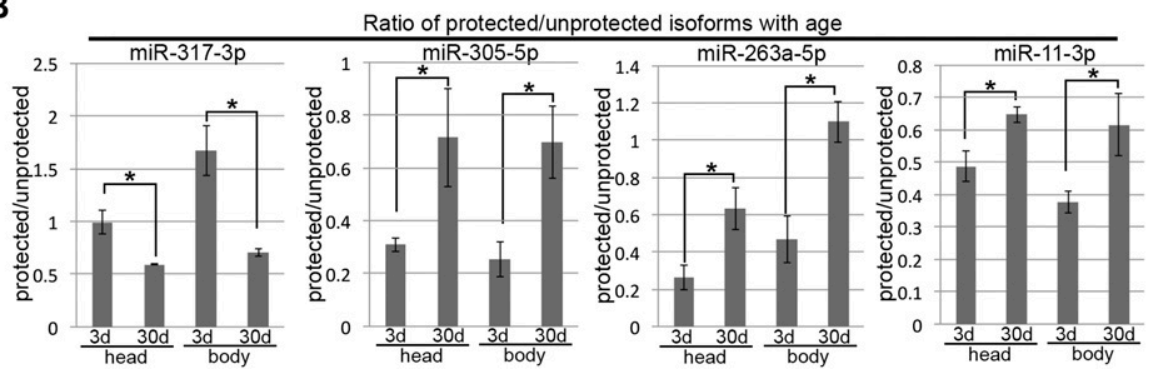

Figure 2. Age-associated increase of long isoforms of miR-305, miR-263a/b, and miR-11 is associated with increased protection from oxidation/ $\beta$-elimination. Northern blots of miR-305, miR-263a/b, miR-11, miR-34, and miR-317 without (left side of each miRNA panel) and with (right side of each miRNA panel) treatment by oxidation/ $\beta$-elimination, with quantitation. (A) All isoforms of miR-34 were sensitive to oxidation/ $\beta$-elimination. The longest isoform of miR-317 was protected (arrowheads), but there was a decrease in the ratio of the protected isoform with age. miR-305, miR-263a/b, and miR-11 show accumulation of a protected long isoform with age (arrows). (B) Ratio of oxidation/ $\beta$-elimination-protected isoforms to unprotected isoforms with age. Mean \pm SD. $n=3 ;\left({ }^{\star}\right) P<0.05$ (Student's $t$-test).

observed to be loaded into Ago2 (Ago2-RISC) and is 2'-Omethylated (Czech et al. 2009; Okamura et al. 2009; Ghildiyal et al. 2010). Therefore, based on our findings, we proceeded to determine whether the protected isoforms of miR-305-5p, miR-263a-5p, and miR-11-3p increased their Ago2 loading with age. To do this, we immunoprecipitated Ago1 and Ago2 from whole flies and then performed Northern blots on the precipitated small RNAs, comparing $3 \mathrm{~d}$ with $30 \mathrm{~d}$. Agol could be immunoprecipitated with an antibody; for Ago2, we used flies bearing a genomically tagged Flag-HA-Ago2 (Czech et al. 2008). This approach revealed a specific loading pattern for each small RNA with age in Agol versus Ago2. miR-34-5p, which was not protected at the 3 ' end (see Fig. 2A), was predominantly loaded into Agol and was not detectably present in Ago2 (Fig. 4A). Consistent with the age-associated pattern of miR-34-5p by Northern from total RNA (see Fig. 1A; Liu et al. 2012), the short isoforms of miR-34-5p accumulated in Agol with age (Fig. 4A). esi-2.1, an abundant endogenous siRNA in flies (Czech et al. 2008; Ghildiyal et al. 2008; Kawamura et al. 2008; Okamura et al. 2008), was selectively loaded into Ago2 and was not detectable in Ago1 (Fig. 4A). In contrast, miR-305-5p and miR-263a-5p showed an intriguing loading pattern: While multiple isoforms were present in Ago1 at both $3 \mathrm{~d}$ and $30 \mathrm{~d}$, only the long isoforms $(24 \mathrm{nt})$ were present in Northerns of Ago2-IP material (Fig. 4A). The single isoform of miR-11-3p was present in Agol; however, a small portion was loaded into Ago2 (Fig. 4A). In addition to the loading of specific lengths of isoforms into Ago2, there was also a trend of increased levels of the loaded isoforms of miR-305-5p, miR-263a-5p, and miR-11-3p into Ago2 with age. To quantify this, we normalized the level of the Ago2-loaded miRNAs to Ago2-loaded esi-2.1 at the corresponding age; the total level of esi-2.1 did not change with age (Fig. 4B) and is loaded into Ago2 and not into Ago1 (Fig. 4A). After normalizing, we confirmed a significant increase of Ago2-loaded miR-305-5p, miR-263a-5p, and miR-11-3p with age (Fig. 4C-E). These findings suggest that the age-associated increase of 2'-O-methylation of miRNAs reflects increased loading of selective isoforms into Ago2 with age.

One possibility for increased loading into Ago2 could be an increase in the level of Hen1, Ago2, and/or the Ago2-loading machinery (Dcr2 and R2D2) with age (Liu et al. 2003; Tomari et al. 2004; Marques et al. 2010; Okamura et al. 2011; Nishida et al. 2013). To address this possibility, we performed Western immunoblots on Ago2 (Flag-HA-Ago2 flies), R2D2, and Dcr2 with age (no antibody is available for Hen1). Both Ago2 and R2D2 were unchanged with age (Fig. 4F-H), and Dcr2 was not detectable in adult flies (Supplemental Fig. S1). To further confirm these results, we examined microarray data from aged Drosophila brains (3 d, $30 \mathrm{~d}$, and $60 \mathrm{~d}$ ) (Liu et al. 2012). Analysis confirmed no significant increase in Hen1, Ago2, Dcr-2, or R2D2 RNA levels with age (Supplemental Table S1). In addition, the level of Agol mRNA and protein was unchanged, suggesting that a decrease in Agol levels would not explain the relative increase in Ago2 loading of miRNAs with age (Supplemental Table S1; Supplemen- 
Abe et al.

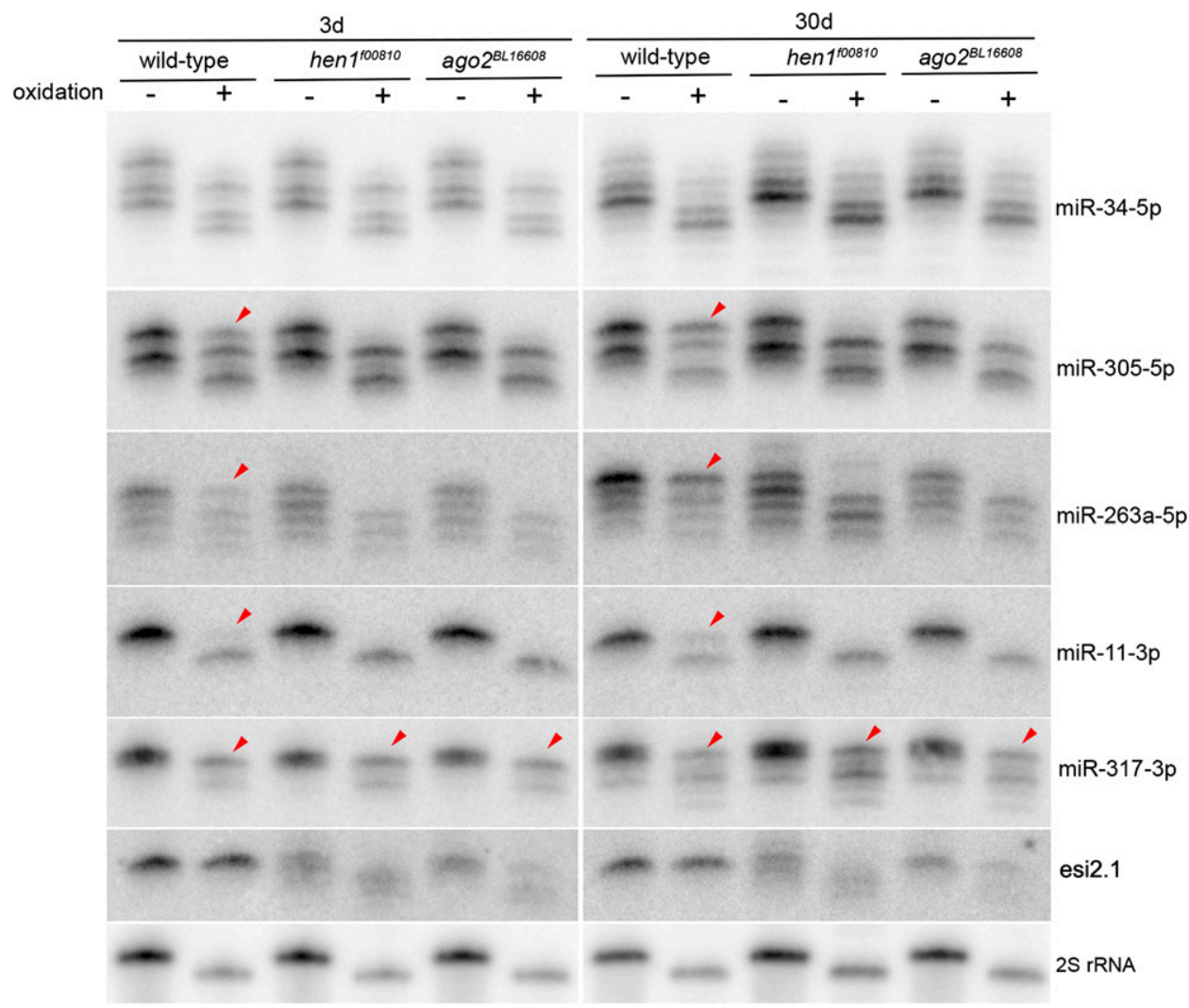

Figure 3. The age-associated increase of the long isoforms of miR-305, miR-263a, and miR-11 is eliminated upon Hen1 and Ago2 mutation. Northern blots of each miRNA with or without oxidation/ $\beta$-elimination at $3 \mathrm{~d}$ and $30 \mathrm{~d}$ in wild-type, Hen $1^{f 00810}$, and $A g O 2^{B L 16608}$ animals. Red arrowheads indicate the isoforms that are protected after oxidation/ $\beta$-elimination in wild type; these forms for miR-305, miR-263a/b, and miR-11 were no longer protected in Hen $1^{f 00810}$ and $A g O 2^{B L 16608}$ mutant animals. The long forms of miR317 remained protected in $\mathrm{Hen}^{f 00810}$ and $A g O 2^{B L 16608}$ animals, indicating an alternative mechanism by which the long isoform accumulates for this miRNA.

tal Fig. S2). We observed a potential increase in mRNA levels for Hsp70 (Supplemental Table S1), a component of RISC-loading machinery, in a complex with Hsp90 (Iki et al. 2010; Iwasaki et al. 2010; Miyoshi et al. 2010). However, since the Hsp90 level is unchanged, there is likely no increase in the Hsp90/Hsp70 complex with age. Together, these results suggest that the increase of Ago2 loading of miRNAs with age is independent of a change in the level of Ago2 or Ago2-loading machinery.

\section{A global shift of Ago1 vs. Ago2-loaded miRNAs with age}

To confirm the increase in miRNA loading into Ago2 with age, we immunopurified Ago1 and Ago2 from flies aged $3 \mathrm{~d}$ and $30 \mathrm{~d}$ and performed deep sequencing of the small RNA fraction. We normalized the number of observed reads to the total number of non-miRNA reads in Agol and to the esi-2.1 reads in Ago2. This analysis showed that the total read number of miRNAs in Agol was largely unchanged, while that of Ago2 increased with age (Fig. 5A). In addition, the share of miRNAs among total small RNAs occupying Agol showed little change with age, while in Ago2, the miRNA reads increased dramatically with age $(30.7 \%$ at $3 \mathrm{~d}$ to $69.6 \%$ at $30 \mathrm{~d})$ (Fig. 5B). During the analysis, we noticed that miR-263a-5p was the singular most abundant miRNA in the 3-d and 30-d Ago2 libraries. Therefore, to rule out that the increased trend of total miRNA reads and percentage in Ago 2 with age simply reflected a change in miR-263a-5p, we also removed miR-263a-5p reads from $3-d$ and $30-d$ Ago2-IP libraries and recalculated the total miRNA read number (normalized to esi-2.1) and the percentage of total miRNAs in 3-d and 30-d Ago2 libraries. This confirmed that, even after removing miR-263a-5p, the trend persisted: The read number and percentage of the total miRNAs in Ago2 increased with age (Supplemental Fig. S3). These results, together with the increased ratio of protected to unprotected isoforms of miRNAs with age (see Fig. 2), support the idea that more miRNA molecules are becoming loaded into Ago2, and not Ago1, with age.

We analyzed in detail the three miRNAs that were the focus of Northern analysis: miR-305-5p, miR-263a-5p, and miR-11-3p. Supporting the earlier observations, miR305-5p, miR-263a-5p, and miR-11-3p showed increased association in Ago2 with age (Fig. 5C, bottom panels). In contrast, the amount of these miRNAs in Agol decreased 
A
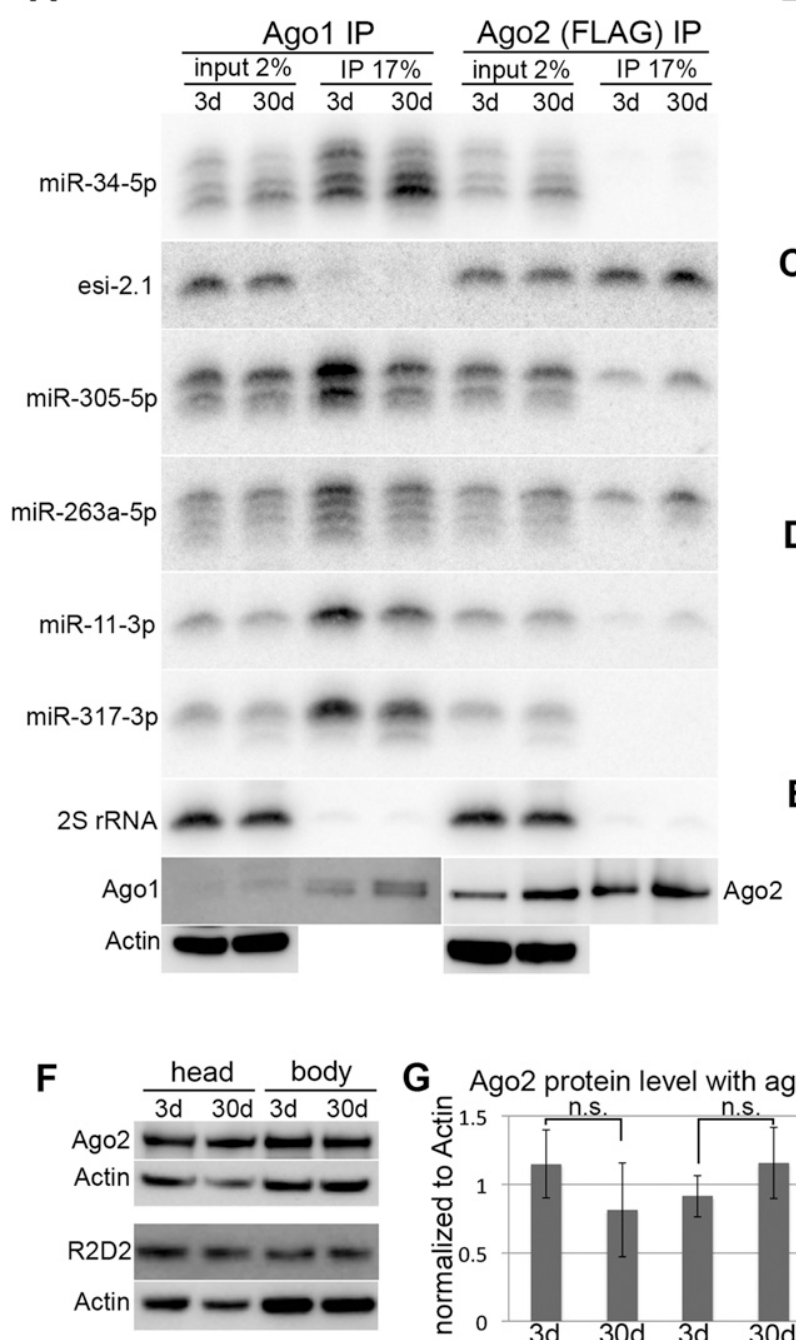

B

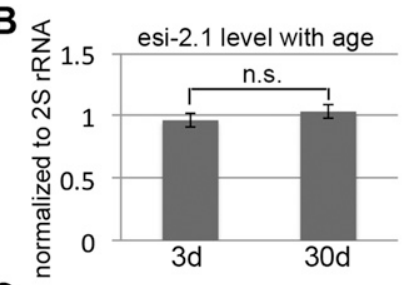

C
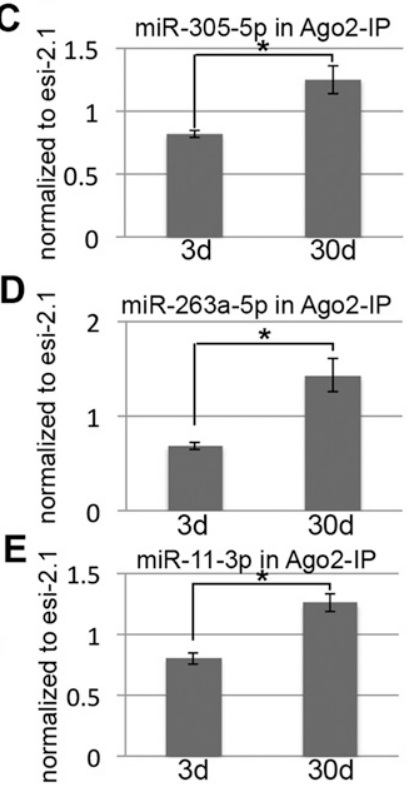

Figure 4. Increased Ago2 loading of long miRNA isoforms with age. Northern blots with quantitation of miRNAs associated with Ago1 versus Ago2 with age. (A) Northern blots for small RNAs on RNA isolated from Ago1-IP (left) and Ago2-IP (Flag-HA-Ago2) (right) . $(B)$ Quantification of esi-2.1 level with age. Mean \pm SD. $n=4$; Student's $t$-test confirmed no significant differences with age. There is no change in esi-2.1 levels with age. $(C-E)$ Quantification of miRNA isoforms loaded into Ago2 with age, normalized to esi-2.1 in Ago2-IP. Mean \pm SD. $n=3 ;\left(^{*}\right) P<0.05$ (Student's $t$-test). For all three miRNAs, the Ago2-loaded isoforms increase with age. $(F)$ Western immunoblot for Ago2 and R2D2 with age. $(G)$ Quantification of Ago2 protein level with age. Mean \pm SD. $n=3$; not significant by Student's $t$-test. $(H)$ Quantification of R2D2 protein level with age. Mean \pm SD. $n=4$; not significant by Student's $t$-test.

with age (Fig. 5C, top panels). Together, these data support the idea that the loading pattern of miRNAs between Ago1 and Ago2 changes dramatically with age such that Ago2 loading of selective miRNA isoforms increases, while Agol loading of the miRNA isoforms generated from the same stem-loops decreases.

Detailed analysis of the libraries allowed identification of additional miRNAs with the same trend of an increase of select isoforms in Ago2 with age. We compared relative loading ratios (Ago2 over Ago1, $R_{21}$ ) (see the Materials and Methods) of the most abundant isoform for each miRNA in 30-d flies versus 3-d flies (Fig. 6A). This showed the three miRNAs that were the focus of our tests with Northerns (miR-305-5p, miR-263a-5p, and miR-11-3p) are among those preferentially loaded into Ago 2 at both $3 \mathrm{~d}$ and $30 \mathrm{~d}$ (Fig. 6A).

Among the 240 Drosophila miRNA genes, 135 were detected with at least one raw read in both Agol-IP and Ago2-IP libraries at $3 \mathrm{~d}$, while 143 were detected at $30 \mathrm{~d}$. Among these, $675 p$ and $3 p$ sequences had at least 1000 raw reads of at least one isoform at $3 \mathrm{~d}$ or $30 \mathrm{~d}$, of which 15 mature and nine star sequences showed preferential loading of specific isoforms into Ago2 relative to Ago1 at $3 \mathrm{~d}\left(R_{21}>1.2\right)$, while 16 mature and nine star sequences showed that trend at $30 \mathrm{~d}\left(R_{21}>1.2\right)$ (Fig. 6A; Supplemental Tables S2, S3). (5p and 3p sequences were classified as "mature" or "star" based on their relative abundance in the Ago1-IP 3-d library and a consistent behavior 
Abe et al.
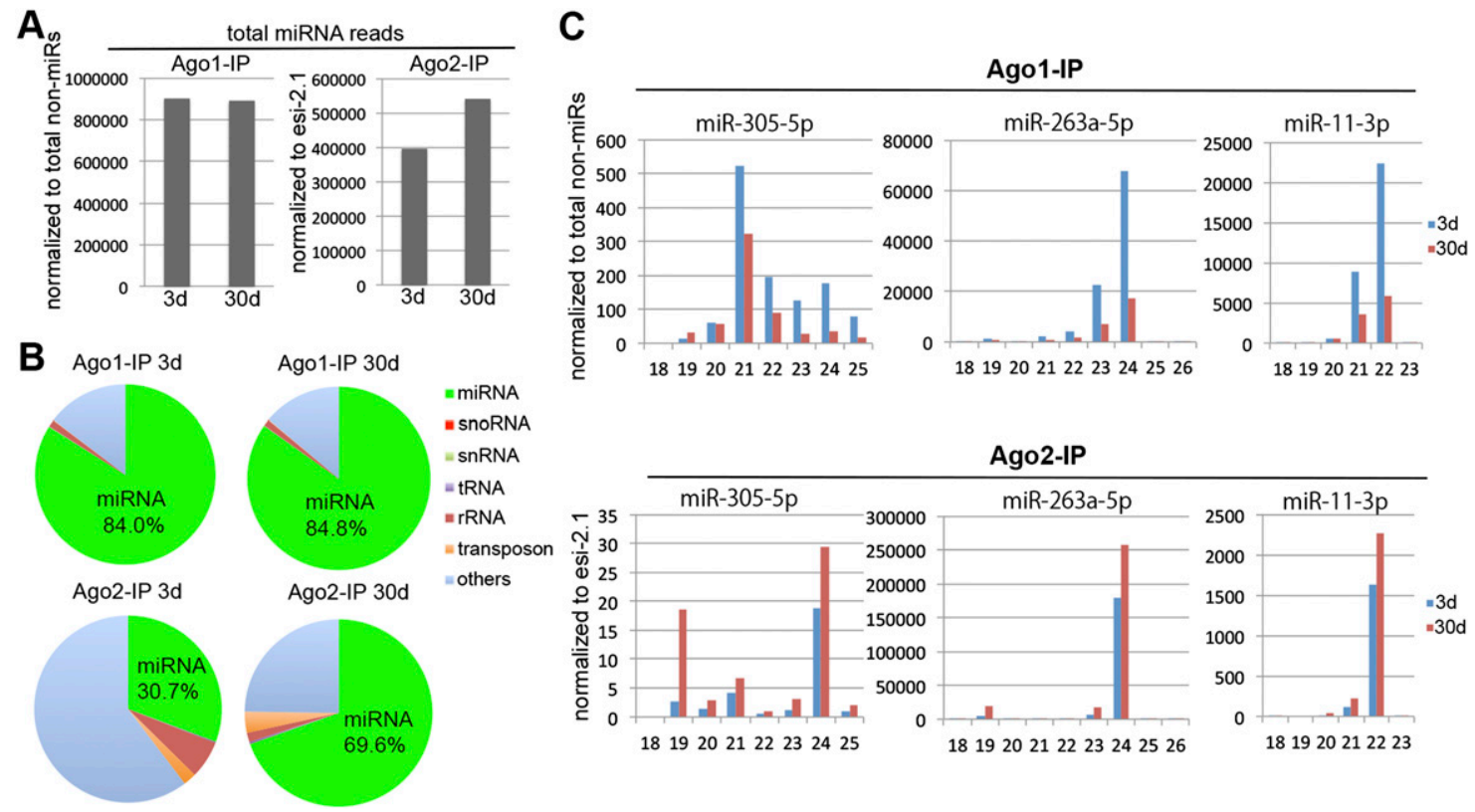

Figure 5. Ago1-IP versus Ago2-IP small RNA deep sequencing with age. (A) Normalized read number of total miRNAs in Agol or Ago2 with age. $(B)$ Percentage of miRNAs and other small RNA classes in Agol and Ago2 with age. $(C)$ miR-305-5p, miR-263a-5p, and miR-11-3p show a decrease in Ago1 but an increase of specific isoforms in Ago2 with age.

across all four libraries: Those with a higher read number compared with the read number from the other strand of the stem-loop were defined as "mature" [see the Materials and Methods for details].)

Next, we determined whether the miRNA isoforms showing preferential loading into Ago2 compared with Agol at either age $\left(R_{21}>1.2\right.$ at $3 \mathrm{~d}$ or $\left.30 \mathrm{~d}\right)$ (Fig. $\left.6 \mathrm{~A}\right)$ also showed an increase in loading into Ago2 with age. To assess the latter value, we calculated for each miRNA the fold change between $30 \mathrm{~d}$ and $3 \mathrm{~d}$ in normalized read numbers of the main isoform loaded into Ago2 (Fig. 6B). A change of more than one would indicate miRNAs with an increase in specific miRNA loading into Ago2 with age. We confirmed that miR-305-5p, miR-263a-5p, and miR11-3p showed increased loading into Ago2 with age (Figs. 4A-E, 6B [red bars]). Together, these data indicate that 11 mature and eight star sequences out of 67 (5p and 3p) total sequences with $>1000$ raw reads of at least one isoform showed preferential loading of specific isoforms into Ago2 relative to Ago1, and such loading increased with age. We also analyzed a library from a previous study comparing Ago1-IP miRNAs to 3' end-protected miRNA from heads (Ghildiyal et al. 2010). This analysis also indicated a selective enrichment for particular miRNAs (Supplemental Fig. 4). From these analyses (Fig. 6B; Supplemental Fig. 4), we then performed Northern blots on several highlighted miRNAs that would be sufficiently abundant to detect in order to examine whether their protection increases with age: miR-1000, miR-100, and miR-8 (Fig. 6B, black arrows; Supplemental Fig. 4, green bars). Northern blots confirmed accumulation of long isoforms protected at the $3^{\prime}$ end that increased in both level and protected isoforms with age (Fig. 6C).
To gain potential insight into the functional effects of the shift in miRNAs from Agol to Ago2 with age, we analyzed gene expression changes in the brain with age, comparing $3 \mathrm{~d}$ with $30 \mathrm{~d}$ from a previous microarray analysis (Liu et al. 2012). We selected down-regulated and up-regulated genes with high stringency $(P<0.001$; Benjamini-Hochberg false discovery rate $[\mathrm{FDR}]<5 \%$ ) with expression change (down or up) above twofold. At $30 \mathrm{~d}$ versus $3 \mathrm{~d}, 719$ genes were significantly downregulated, and 199 were significantly up-regulated, giving a global ratio of age-related down-regulation of 3.61 for the whole genome. We then considered the potential effects of miRNAs with increased loading into Ago2 by deep sequencing that were confirmed by Northerns (miR1000, miR-100, miR-305, miR-11, miR-263a, miR-263b, and miR-8). In a combined list of mRNA targets of these miRNAs (predicted by TargetScan), the down-regulation ratio was substantially higher $(104 / 13=8 ; P<0.001$; Benjamini-Hochberg FDR $<5 \%$ ); thus, these target genes are twice as likely to show stronger down-regulation with age compared with the whole genome. We further analyzed the splicing array data of Taliaferro et al. (2013) following knockdowns of Ago proteins in S2 cells. Although these arrays were designed for quantifying alternative splicing rather than gene expression, they still show trends consistent with our observations. Of 159 deregulated genes with Agol knockdown, eight predicted targets of the miRNAs shifted to Ago2 showed changed expression (down-regulated, except for the cals gene); all were also down-regulated in the aging microarray at $30 \mathrm{~d}$ versus $3 \mathrm{~d}$. Among the 51 deregulated genes in Ago2 knockdown, four predicted targets of the miRNAs shifted to Ago2 showed a change of expression, but it was up- 

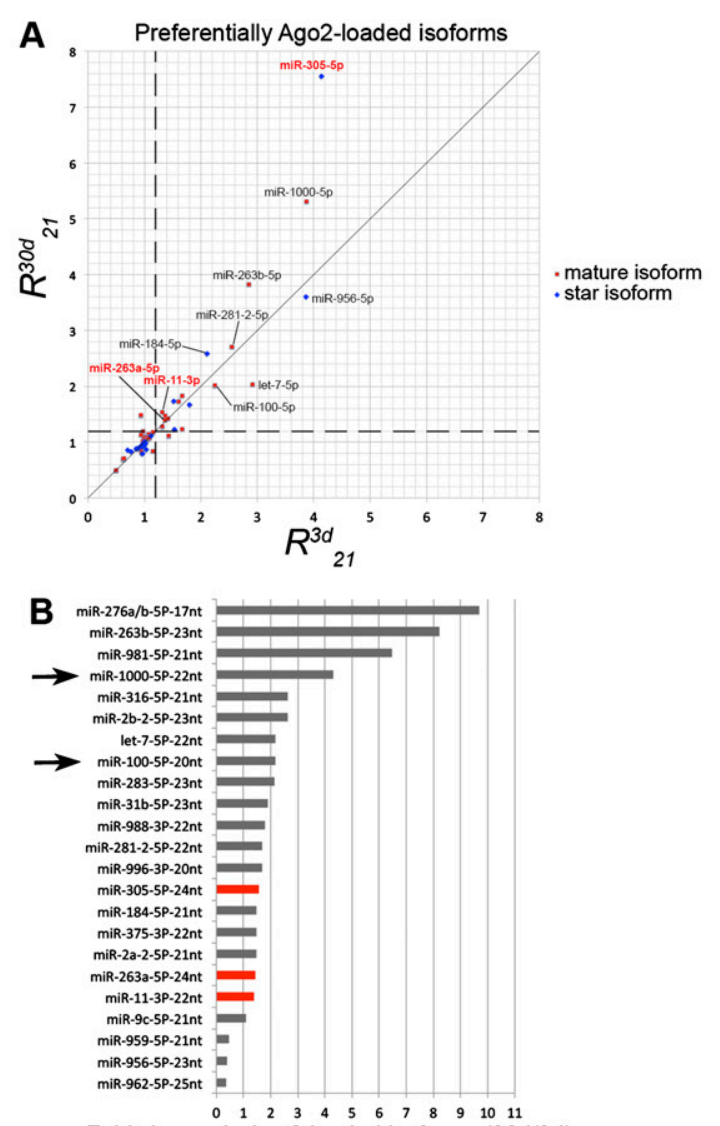

Fold change in Ago2-loaded isoforms (30d/3d)

\section{C}
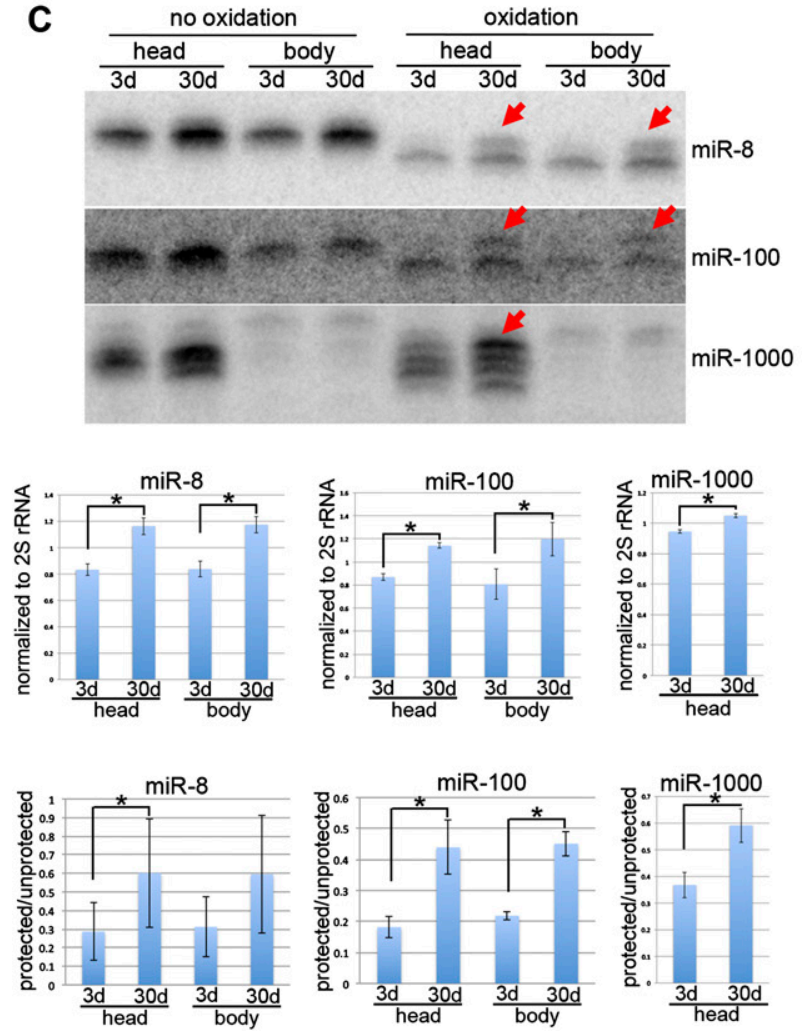

regulation (except for the $b b c$ gene), while they were down-regulated in the aging microarray at $30 \mathrm{~d}$ versus $3 \mathrm{~d}$. Thus, for the group of genes in common, there is a striking reversal of expression following Ago2 knockdown, but not Ago1 knockdown, compared with the general downregulation with age.

\section{Loss of Hen1 and Ago2 is associated with shortened life span and neurodegeneration}

To address the biological significance of the global shift in the population of Ago2-loaded miRNAs, we examined the impact of global loss of 2'-O-methylation of small RNAs by analyzing Hen1 and Ago2 mutant animals. Ago2 loss is known to cause defects in synaptic structure in third instar larvae (Pepper et al. 2009), indicating the importance of $\mathrm{AgO} 2$ on neuronal development. Here we focused on adult-specific age-associated effects. Life span analysis indicated that both $\mathrm{Hen}^{f 00810}$ and $\mathrm{AgO} 2^{\mathrm{BL} 16608}$ mutants showed a shorter life span compared with genetic background-matched controls (Fig. 7D). Detailed analysis of these animals also showed that both Hen $1^{f 00810}$ and Ago2 $\left(\mathrm{Ago}^{414}\right.$ and $\left.\mathrm{AgO} 2^{\mathrm{BL16608}}\right)$ mutants have increased brain vacuolization, indicative of brain degeneration with age (Fig. 7A-C). While Hen1 $1^{f 00810}$ mutants showed more brain vacuolization in the optic lamina (Fig. 7B), Ago2 mutants had excessive vacuoles in the retina (Fig. 7C). Both Hen1 and Ago2 mutants are predicted to impact siRNAs, which may contribute to the effects, and the difference in phenotypes between Hen1 and Ago2 mutants might reflect a broader role of $A g o 2$ beyond its effects on siRNAs (Taliaferro et al. 2013). However, defects in both Hen1 and Ago2 mutants suggest that 2'-O-methylation of

Figure 6. Identification of Ago2-loaded miRNA isoforms whose loading increases with age. $(A)$ Dot plot showing the ratio of preferentially Ago2-loaded isoforms at $3 \mathrm{~d}$ ( $X$-axis) to $30 \mathrm{~d}$ (Y-axis). We selected miRNAs with values $R_{21}>1.2$ as candidates with greater loading into Ago 2 at $3 \mathrm{~d}$ or $30 \mathrm{~d}$ (dashed lines parallel to the axes; miR-305-5p, miR-263a-5p, and miR11-3p are seen) (full lists are in Supplemental Tables S2, S3). miR-34-18nt, miR-276a/b-5p-17nt, and miR-981-5p-21nt showed an extremely high $R_{21}$ ratio at $3 \mathrm{~d}$ and/or $30 \mathrm{~d}(>16)$ (Supplemental Tables S2, S3). This suggests much higher accumulation of these miRNA isoforms in Ago2-IP compared with Agol-IP at 3 $\mathrm{d}$ and/or $30 \mathrm{~d}$. This could happen because of biologically relevant up-regulation of these miRNA isoforms or cloning bias and degradation from the corresponding longer isoforms. These miRNA isoforms were removed from this figure because including these data obscured the distribution of the other data in the plot. miR-34-18nt was undetectable by Agol-IP versus Ago2-IP Northerns. Therefore, most- likely, miR-34-18nt is an artifact of library preparation. (B) Fold change of the main isoform of preferentially Ago2-loaded miRNA isoforms with age ( $30 \mathrm{~d} / 3 \mathrm{~d})$. Red indicates miRNAs known from our Northern analyses that show an increase in Ago2 association with age. Black arrows here and green bars in Supplemental Figure 4 indicate abundant miRNAs that were tested for accumulation in Ago2 with age in $C$. $(C)$ Northern analysis $(t o p)$ and quantitation (bottom) of miRNAs highlighted by the analyses in $B$ and Supplemental Figure 4. 
Abe et al.
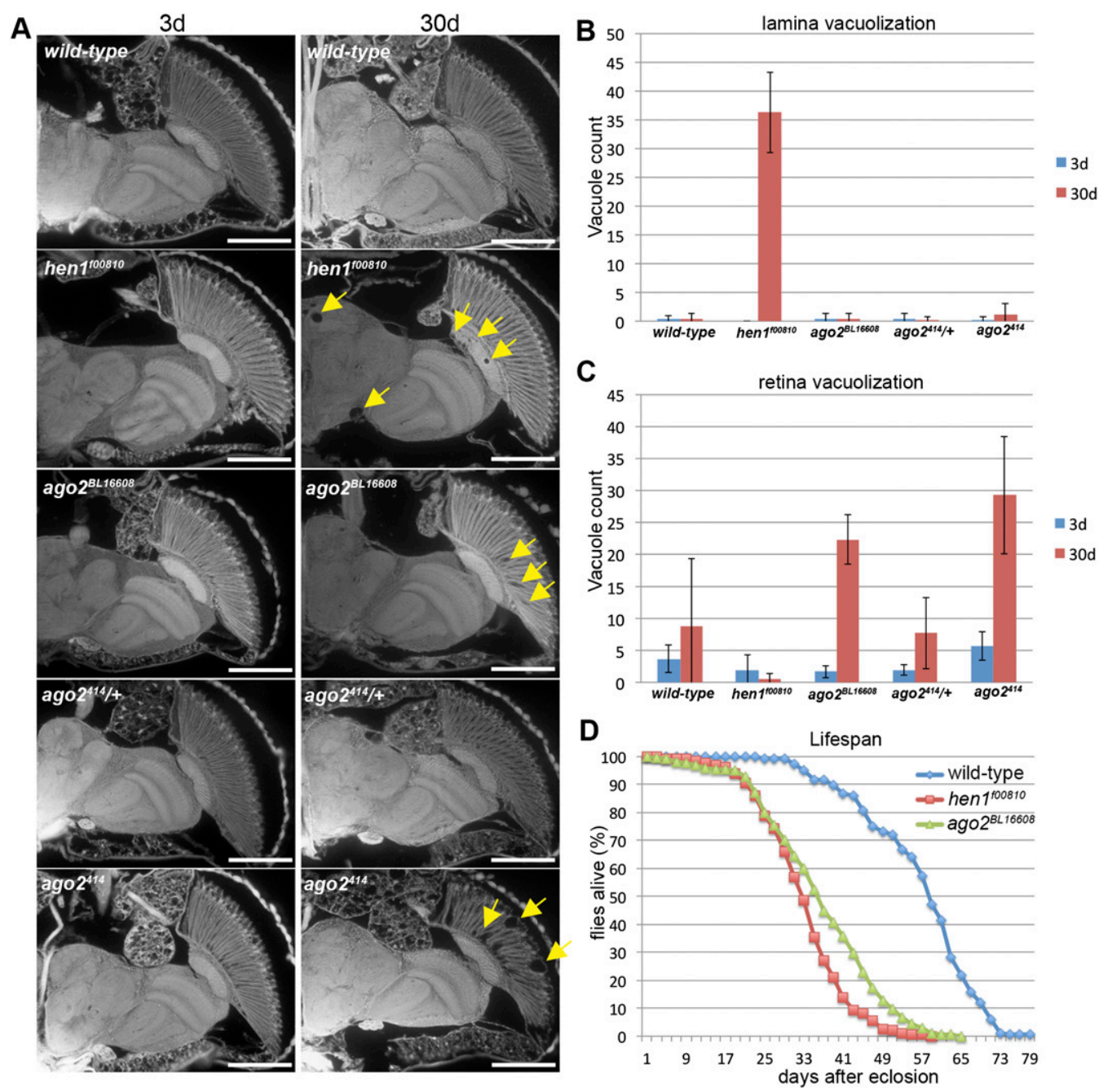

Figure 7. Mutations in Hen1 and Ago2 are associated with age-dependent brain degeneration and shorter life span. $(A)$ Paraffin sections of wild-type, $\operatorname{Hen}^{f 00810}, A g O 2^{B L 16608}, A g O 2^{414} /+$, and $A g O 2^{414}$ heads at $3 \mathrm{~d}$ and $30 \mathrm{~d}$. Bar, $0.1 \mathrm{~mm}$. The abundant vacuoles that are present in 30-d animals in the mutants are highlighted in yellow. (B) Quantification of brain vacuoles in lamina. $(C)$ Quantification of brain vacuoles in retina. $(D)$ Life span of wild-type, Hen1 ${ }^{f 00810}$, and $A g o 2^{B L 16608}$ mutants. Mutant lines have been backcrossed into the genetic background of the control wild type (see the Materials and Methods). The life spans of the mutants are significantly different from wild type. $P<0.0001$ for each compared with wild type; $\log$ rank analysis; $\chi^{2}$ value with $H e n 1^{f 00810}$ is 327.7 ; $\chi^{2}$ value with $\mathrm{AgO}^{\mathrm{BL} 16608}$ is 253.3 .

small RNAs, one class of which is miRNAs, is critical for age-associated processes in Drosophila.

\section{Discussion}

Dynamic regulation of Ago1 vs. Ago2 loading of miRNAs with age

Increasing evidence suggests that miRNAs show heterogeneity at the $5^{\prime}$ end and $3^{\prime}$ end and even in precise sequence in different cell types and biological contexts (Neilsen et al. 2012). Despite this, it is less understood whether and how such heterogeneity is regulated biologically or its biological impact. Here, by examining the age-associated pattern of miRNA isoforms, we show that 2 '-O-methylation of miRNAs changes in an age-depen- dent manner in Drosophila. This change is correlated with a shift in partitioning of miRNAs into Ago2 versus Agol with age. These data suggest that the partitioning of miRNAs between Agol and Ago2 is modulated with age in Drosophila.

The mechanism of miRNA loading into the different Ago complexes in Drosophila, especially in vivo, remains unclear. Previously, miR-277 was shown to be loaded into both Ago1 and Ago2 because of the lack of an extensive central bulge in the miR-277/miR-277 ${ }^{\star}$ duplex (Forstemann et al. 2007). However, our analysis of the miRNAs that show higher levels of 2'-O-methylation with age failed to identify a consistent lack of central bulges on miRNA/miRNA* duplexes (Supplemental Fig. S5). Rather, our results indicate that miRNA isoforms with the same sequence and length can be partitioned into both Ago1 and Ago2 and 
that a change in this distribution is an age-associated phenomenon. This effect, at least in vivo, is likely to be driven by a bulge-independent mechanism. Bulge-independent partitioning of small RNAs into different Ago complexes is suggested from other studies as well: The loop sequence from miR-34 precursor stem-loop is abundant in some cells and loaded into Agol despite its single-stranded nature (Okamura et al. 2013).

In vivo significance of differential partitioning of miRNAs between Ago1 and Ago2 with age

Our analyses of Hen1 and Ago2 mutants suggest that 2'$O$-methylation of small RNAs affects age-associated traits of brain degeneration and life span. In addition to effects on other small RNA classes, it is possible that the loss of 2'-O-methylation of miRNAs leads to destabilization of the miRNAs, thus affecting target silencing and contributing to accelerated age-associated defects. In this case, Ago2-loaded, but not Agol-loaded, miRNAs would be selectively affected. Interestingly, both Ago1 and Ago2 are active in silencing miRNA targets. However, Drosophila Ago1 and Ago2 use different mechanisms to silence target mRNAs, as silencing by let-7 Agol-RISC entails the removal of the polyA tail, whereas that by let-7 Ago2-RISC entails retention of the polyA tail (Iwasaki et al. 2009). Such mechanistic differences might contribute to the differential silencing efficiency of the two Ago complexes of the reporters: let-7 Agol-RISC is more efficient than let-7 Ago2-RISC in silencing the reporters (Iwasaki et al. 2009). Our analysis of gene expression changes with age indicates a global downregulation in the brain; correlating this with Agol versus Ago2 knockdown data in cells indicates greater downregulation of predicted mRNA targets of miRNAs shifted to Ago2. While we cannot exclude that such changes result from other activities of Ago2 (Taliaferro et al. 2013), the observed reversal of expression is also consistent with a model of regulation resulting from increased loading of miRNAs shifted to Ago2 with age. Thus, potentially, the shift of these miRNAs into Ago2 may affect downregulation of their targets with age, and disruption of this process in Hen1 and Ago2 mutants, along with effects on other small RNAs, may contribute to the life span and neurodegenerative phenotypes observed. Further experimental testing of the effects on mRNA targets by the miRNAs when loaded into Ago1 versus Ago2 may reveal specific details regarding the functional effects of the partitioning of the miRNAs between the RISCs and the biological outcomes.

An interesting possibility is that, by shifting miRNAs toward Ago2 from Ago1 with age, the organism might be adjusting the efficiency of target gene expression for ongoing or upcoming age-associated stresses. Since Ago2-mediated translational silencing causes retention of the polyA tail (Iwasaki et al. 2009), this might make it possible to respond to age-associated internal or external stresses more rapidly by reactivation of target mRNAs. Another possibility is the effect of loss of 2'-O-methylation on other classes of small RNAs, such as endo-siRNAs or
piRNAs (Horwich et al. 2007; Czech et al. 2008; Ghildiyal et al. 2008; Kawamura et al. 2008; Okamura et al. 2008). Loss of Ago2 leads to decreased production of endosiRNAs, which is correlated with up-regulation of transposons (Czech et al. 2008; Ghildiyal et al. 2008; Kawamura et al. 2008; Okamura et al. 2008). Recently, an ageassociated increase of transposon expression and shorter life span were noted in Ago2 mutants (Li et al. 2013). Although Ago2 mutants show developmental defects (Pepper et al. 2009), both Hen1 $1^{f 00810}$ and Ago2 mutants are maintained in homozygous condition, and the overall brain morphology and climbing activity of these mutants when young are normal (see Fig. 7). Although it is possible that loss of these gene activities during development might sensitize the adult state, taken together, these data suggest that the defects observed in adult Hen1 and Ago2 mutants more likely reflect defects in adult age-associated processes. These findings support the importance of terminal modification of small RNAs on impacting ageassociated traits.

\section{Dynamic miRNA isoform regulation with age}

It has become evident that the pattern of miRNA isoforms varies in different biological contexts, such as different stages of development, different tissues, and disease (Fernandez-Valverde et al. 2010; Marti et al. 2010; Li et al. 2012; Neilsen et al. 2012; Llorens et al. 2013). It is also becoming evident that such isoform distributions are regulated (Neilsen et al. 2012). For example, Nbr defines the 3' end of many Drosophila miRNAs (Han et al. 2011; Liu et al. 2011), and Loqs-PB (Drosophila homolog of TRBP) partnering with Dcr-1 defines the cleavage position of several Drosophila miRNAs, which seems conserved in mammals as well (Fukunaga et al. 2012; Lee and Doudna 2012). Our study reveals another repertoire of biological heterogeneity of miRNAs: differential 2'-Omethylation of miRNA with age. It is intriguing that the loss of such miRNA heterogeneity leads to clear biological defects (M Abe and N Bonini, unpubl.; this study). These results raise the possibility that, in the aging adult, fine-tuning of miRNA heterogeneity might be critical for combating age-associated stresses.

\section{Materials and methods}

\section{Small RNA Northern hybridization}

Total RNA was extracted from fly tissues using Trizol reagent (\#15596-018, Life Technologies) following the manufacturer's protocol. Three micrograms to $\sim 10 \mu \mathrm{g}$ of total RNA was loaded per lane in 15\% TBE-urea gel (\#EC6885BOX, Life Technologies) and then transferred to nylon membrane (Hybond N+, GE Healthcare). After UV cross-linking and prehybridization $(1 \mathrm{~h}$ at $50^{\circ} \mathrm{C}$ ), the membranes were hybridized with $\mathrm{P}^{32}$-labeled probes overnight at $50^{\circ} \mathrm{C}$. DNA oligonucleotides were annealed to obtain the templates for RNA probes. The sequences of the DNA oligonucleotides used to make probes were miR-34-5p (5'GATAATACGACTCACTATAGGGAGA-3' $/ 5^{\prime}$-AAAAAATGGC AGTGTGGTTAGCTGGTTGTGTCTCCCTATAGTGAGTCG TATTATC-3'), miR-263a-5p (5'-GATAATACGACTCACTAT AGGGAGA-3'/5'-GTTAATGGCACTGGAAGAATTCACTCTC 
CCTATAGTGAGTCGTATTATC-3'), miR-305-5p (5'-GATAA TACGACTCACTATAGGGAGA-3' $/ 5^{\prime}$-AAAAAAATTGTACTTC ATCAGGTGCTCTGTCTCCCTATAGTGAGTCGTATTATC3'), miR-317-3p (5'-GATAATACGACTCACTATAGGGAGA-3') 5'-AAAAAAATGAACACAGCTGGTGGTATCCAGTTCTCCCT ATAGTGAGTCGTATTATC-3'), esi2.1 (5'-GATAATACGACTC ACTATAGGGAGA-3' $/ 5^{\prime}$-TTGACTCCAACAAGTTCGCTCCTC TCCCTATAGTGAGTCGTATTATC-3'), miR-8 (5'-GATAATAC GACTCACTATAGGGAGA-3'/5' -AAAAAATAATACTGTCAGG TAAAGATGTTCTCCCTATAGTGAGTCGTATTATC-3' ${ }^{\prime}$, miR 100 (5'-AAAAAAAACCCGTAAATCCGAACTTGTGTCTCCC TATAGTGAGTCGTATTATC-3'), miR-1000 (5'-GATAATACG ACTCACTATAGGGAGA-3' $/ 5^{\prime}$-AAAAAAATATTGTCCTGTCA CAGCAGTTCTCCCTATAGTGAGTCGTATTATC-3'), and 2S rRNA $\left(5^{\prime}\right.$-GATAATACGACTCACTATAGGGAGA-3' $/ 5^{\prime}$-TGC TTGACTACATATGGTTGAGGGTTGTATCTCCCTATAGTG AGTCGTATTAT C-3'). $\mathrm{P}^{32}$-labeled probes were synthesized by in vitro transcription using MAXIscript T7 kit (\#AM1312, Life Technologies), supplemented with $\mathrm{P}^{32}$ - $\alpha$-UTP.

\section{Oxidation/ $\beta$-elimination of RNA}

Total RNA was extracted from fly tissues using Trizol reagent (\#15596-018, Life Technologies) following the manufacturer's protocol. Total RNA was resuspended in $1 \times$ borate/borax buffer with or without $\mathrm{NaIO}_{4}$ (final concentration $25 \mathrm{mM}$ ) (\#311448, Sigma-Aldrich) and incubated for $30 \mathrm{~min}$ at room temperature in the dark. After adding 1/10 vol of $100 \%$ glycerol, the samples were incubated further for $10 \mathrm{~min}$ at room temperature in the dark. After purifying the RNA, the RNA samples were resuspended in $1 \times$ borate/borax buffer and supplemented with $\mathrm{NaOH}$ to a final concentration of $0.1 \mathrm{mM}$. The samples were incubated for $90 \mathrm{~min}$ at $45^{\circ} \mathrm{C}$ followed by purification and analysis by Northern blots. Ten micrograms to $\sim 20 \mu \mathrm{g}$ of total RNA was used for each miRNA.

\section{IP-Northern}

Fly lysate was prepared from 3-d and 30-d male Flag-HA-Ago2 whole flies (Czech et al. 2008). Approximately 80 flies were used for each IP (Ago1 or Ago2) followed by Northerns (miR-34-5p, esi-2.1, miR-305-5p, miR-263a-5p, miR-11-3p, and miR-317-3p). Immunoprecipitation was performed as described (Kirino et al. 2011), except that $800 \mathrm{mM} \mathrm{NaCl}$ (final concentration) was used for Ago2-IP. Anti-Ago1 (ab5070, Abcam) and M2 beads (\#A2220, Sigma-Aldrich) were used for Ago1 and Ago2-IP, respectively. After extraction of RNA from beads as described in Kirino et al. (2011), the purified RNA was loaded onto 15\% TBE-urea gel followed by Northern blots.

\section{Preparation of Ago1 and Ago2-IP small RNA libraries}

Forty whole male flies (Flag-HA-Ago2, $3 \mathrm{~d}$ and $30 \mathrm{~d}$ ) were used for Ago1-IP, and 200 whole male flies ( $3 \mathrm{~d}$ and $30 \mathrm{~d})$ were used for Ago2 (M2)-IP. After immunoprecipitation of Ago1 or Ago2, the purified RNA was $\mathrm{P}^{32}$-labeled as described (Kirino et al. 2011), and the radiolabeled RNA was run on a 15\% TBE-urea gel (\#EC6885BOX, Life Technologies). The gel was exposed to a PhosphorImager screen, and the fractions corresponding to small RNAs were excised from the gel. After purifying the small RNAs from the gel, small RNA libraries were generated using Illumina's TruSeq small RNA sample preparation kit (\#RS-200-0012, Illumina, Inc.) following the manufacturer's protocol. The libraries were sequenced on a HiSeq2000 platform (Illumina).

\section{Western immunoblots}

Fly tissues were resuspended in RIPA buffer followed by grinding and centrifugation to remove debris. The supernatant was measured by Bradford assay, and $25 \sim 50 \mu \mathrm{g}$ of protein was loaded onto each lane. NuPAGE Novex 4\%-12\% Bis-Tris gel (\#NP0321BOX, Life Technologies) was used to run the samples in $1 \times$ NuPAGE MES SDS running buffer (\#NP0002, Life Technologies). Proteins were transferred to PVDF membrane, and the membrane was blocked by $5 \%$ milk/TBST for $1 \mathrm{~h}$ at $4^{\circ} \mathrm{C}$. The membrane was incubated with primary antibody overnight at $4^{\circ} \mathrm{C}$. After washing the membrane in TBST buffer three times (5 min each), the membrane was incubated with secondary antibody for $2 \mathrm{~h}$ at $4^{\circ} \mathrm{C}$. The membrane was washed in TBST three times (5 min each) followed by signal development by Pierce ECL plus Western blotting substrate (\#32132, Thermo Fisher Scientific). The image was scanned by a Fujifilm LAS-3000 Imager (Fujifilm). For Ago2 Western, Flag-HA-Ago2 male flies were used. For R2D2 and Dcr2 Western blot, wild-type male flies were used. The primary antibodies used were anti-Flag-HRP (1:2000; \#A8592, SigmaAldrich) for Ago2. Anti-Agol (1:500-1:1000) for Westerns was a kind gift of the Mourelatos laboratory. Anti-R2D2 (rabbit polyclonal) and anit-Dcr2 (mouse monoclonal) antibodies were kind gifts from the Siomi laboratory. Anti-Actin Ab (Ab8227, Abcam) was used at 1:2000. The secondary antibodies used were antimouse IgG-HRP (1:2000; \#7076S, Cell Signaling Technology, Inc.) and anti-rabbit IgG-HRP (1:2000; \#sc-2030, Santa Cruz Biotechnology, Inc.).

\section{Fly stocks}

Flies were grown in standard cornmeal molasses agar medium at $25^{\circ} \mathrm{C}$. Hen $1^{f 00810}$ (FlyBase ID: FBst1016506, The Exelixis Collection at the Harvard Medical School) and $\mathrm{Ago}^{414}$ (FlyBase ID: FBst0313641, Drosophila Genetic Resource Center, Kyoto Stock Center) flies were kind gifts from the Sara Cherry laboratory. Ago2 ${ }^{\text {BL16608 }}$ (FlyBase ID: FBst0016608) and Flag-HA-Ago2 flies (FlyBase ID: FBst0033242) were obtained from the Bloomington Stock Center. Hen $1^{f 00810}$ and $A g O 2^{B L 16608}$ lines were backcrossed into a homogenous wild-type background (Bloomington Stock Line 5905 [BL5905], FlyBaseID: FBst0005905, $w^{1118}$ ) for five generations.

\section{Life span assay}

One-hundred-eighty to $\sim 200$ flies were used for each life span replicate. Male flies were collected on the day of eclosion (15 flies per vial), aged at $25^{\circ} \mathrm{C}$, and transferred to new fly food vials every other day while scored for survival. The assay was repeated in triplicate and was analyzed by Excel (Microsoft) and GraphPad Prism for survival curves.

\section{Brain paraffin sections}

Adult female heads ( $3 \mathrm{~d}$ and $30 \mathrm{~d}$ ) were used for paraffin sections as described (Li et al. 2008). Brain vacuoles were counted for lamina or retina through 10 continuous horizontal sections, defining the center section, with esophagus being most prominent. Four heads per genotype were used for quantification.

\section{Computational analyses}

Mapping and histograms Adaptor sequences were removed from the $3^{\prime}$ ends of the reads in the Illumina fastQ-generated files using the fastx toolkit (http://hannonlab.cshl.edu/fastx_toolkit). The adapter sequences were as follows: $5^{\prime}$ adapter, 5'-GUUCA- 
GAGUUCUACAGUCCGACGAUC-3'; and 3' adapter, 5'-TGG AATTCTCGGGTGCCAAGG-3'.

Reads were then collapsed and annotated with the number of times each was sequenced, and only unique reads were analyzed. Reads were filtered based on base-pair size such that reads $<16$ base pairs $(\mathrm{bp})$ or $>30 \mathrm{bp}$ were discarded. The remaining reads were then mapped using Bowtie to the Drosophila melanogaster (dm5) genome and miRNA stem-loop sequences obtained from miRBase (release 20). Bowtie parameters were restricted to output only perfectly aligned matches to the stem-loop sequence. The reads were aligned and mapped to entire miRNA stem-loops. After aligning, each read was annotated as either a $5 \mathrm{P}$ or a $3 \mathrm{P}$. To do this, the stem-loop sequence was split in half, with the first half designated the $5^{\prime}$ arm and the second half designated the $3^{\prime}$ arm, as the start and end positions of most miRNAs are imprecise.

Change in the read number and percentage of total miRNAs and other classes of small RNAs All processed reads were first mapped to transposons annotated by FlyBase (ftp://ftp.flybase.net/ genomes/Drosophila_melanogaster/current/fasta). The rest of the reads were stored and mapped to miRNA stem-loop regions as well as known ncRNAs (snRNAs, snoRNAs, tRNAs, and rRNAs) and the rest of the genome (defined as "ncRNA" and "genome" by FlyBase).

Identification of preferentially Ago2-loaded miRNA isoforms at $3 d$ and $30 d$ We identified miRNA isoforms preferentially loaded into Ago2 compared with Agol for flies of different ages using a measure of "Ago2/Ago1 relative load ratio" or $R_{21}$. The most abundant isoform from each miRNA stem (5p or $3 p)$ from the Ago2-IP 3-d library was selected. For all of the isoforms in each library that start with the same $5^{\prime}$ nucleotide position, we denoted the share of each isoform $s_{i}^{l i b}$ such that $\sum_{i} s_{i}^{l i b}=1$ in each library and denoted the share of the most abundant isoform $S^{\text {lib }}$. The age ratio for 3-d flies was $R_{21}^{3 d}=S^{3 d A g o 2} / S^{3 d A g o 1}$ ( $X$-axis in Fig. 6A), and the age ratio for 30-d flies was $R^{30 d}=S^{30 d A g o 2} /$ $S^{30 d A g o 1}$ (Y-axis in Fig. 6A). 5p and 3p miRNA stem sequences were classified as "mature" and "star" based on their relative (high and low, respectively) deep sequencing read counts in the Agol sample at $3 \mathrm{~d}$ (strand with $S^{3 d A g o 1}$ being the mature strand). To compare the ratio of a specific isoform between Agol and Ago2, after assigning to the "mature" or "star" category, we kept only the cases with the mature and star categories consistent among all four libraries. Thus, if there was a discrepancy of the relatively more abundant stem (5p or $3 p$ ) between Agol-3d and any of the other three libraries (Ago2-3d, Ago1-30d, and Ago2$30 \mathrm{~d})$, those cases were removed. This was to assure that the same isoform was consistently called "mature" or "star" in all four libraries (Ago1-3d, Ago1-30d, Ago2-3d, and Ago2-30d). We also filtered out any miRNAs that were below a 1000 read count threshold. Note that miR-34-18nt, miR-276a/b-5p-17nt, and miR-981-5p-21nt showed an extremely high $R_{21}$ ratio at $3 \mathrm{~d}$ and/or $30 \mathrm{~d}(>16)$ (Supplemental Tables S2, S3). This suggests much higher accumulation of these miRNA isoforms in Ago2-IP compared with Agol-IP at $3 \mathrm{~d}$ and/or $30 \mathrm{~d}$. This could happen due to either biologically relevant up-regulation of these miRNA isoforms or cloning bias or degradation from the corresponding longer isoforms. These miRNA isoforms were removed from Figure 6 because including the dots corresponding to these miRNA isoforms obscured the distribution of the other dots in the plot (see Fig. 6A). miR-34-18nt was undetectable by Ago1 versus Ago2-IP Northerns; therefore, most likely, miR-34-18nt is an abnormal by-product of the library preparation. After identifying preferentially loaded Ago 2 isoforms, we calculated a ratio of normalized reads at $30 \mathrm{~d}$ and $3 \mathrm{~d}$ for each specific isoform. The ratios (fold change) were plotted as in Figure 6B. To check for selective enrichment of particular miRNAs from the data of Ghildiyal et al. (2010), we first identified the most abundant isoform for each miRNA in the total RNA set (GSM466487). For each of the libraries (GSM466488 and GSM466489), we counted the number of reads $(M)$ for these isoforms and calculated their relative enrichment as $E=N /(N-M)$, where $N$ is the total number of library reads for a given miRNA. We then plotted the enrichment ratio $E_{G S M 466488} / E_{G S M 466489}$ in Supplemental Figure 4. Note that we used both sequence analysis for discovery of new Ago2 preferentially loaded miRNAs (see Fig. 6A,B; Supplemental Fig. 4) and Northern analysis (see Fig. 6C), as each technique (deep sequencing and Northern analysis) will have strengths and weaknesses. The Gene Expression Omnibus record for libraries generated here is GSE52963. We also analyzed previously published microarray data GSE25009 from Liu et al. (2012) and data from Taliaferro et al. (2013).

\section{Acknowledgments}

We thank members of the Bonini laboratory for critical reading, Xiuyin Teng for outstanding technical assistance, and Matthew Taliaferro and Dr. Donald Rio for kindly sharing data. This work was funded in part by the Ellison Medical Foundation (to N.M.B.), and the National Science Foundation (grant DBI-1126052 to A.G.).

\section{References}

Alon S, Mor E, Vigneault F, Church GM, Locatelli F, Galeano F, Gallo A, Shomron N, Eisenberg E. 2012. Systematic identification of edited microRNAs in the human brain. Genome Res 22: 1533-1540.

Ameres SL, Horwich MD, Hung JH, Xu J, Ghildiyal M, Weng Z, Zamore PD. 2010. Target RNA-directed trimming and tailing of small silencing RNAs. Science 328: 1534-1539.

Azuma-Mukai A, Oguri H, Mituyama T, Qian ZR, Asai K, Siomi H, Siomi MC. 2008. Characterization of endogenous human Argonautes and their miRNA partners in RNA silencing. Proc Natl Acad Sci 105: 7964-7969.

Bartel DP. 2004. MicroRNAs: Genomics, biogenesis, mechanism, and function. Cell 116: 281-297.

Boehm M, Slack F. 2005. A developmental timing microRNA and its target regulate life span in C. elegans. Science 310: 1954-1957.

Burroughs AM, Ando Y, de Hoon MI, Tomaru Y, Nishibu T, Ukekawa R, Funakoshi T, Kurokawa T, Suzuki H, Hayashizaki $\mathrm{Y}$, et al. 2010. A comprehensive survey of $3^{\prime}$ animal miRNA modification events and a possible role for $3^{\prime}$ adenylation in modulating miRNA targeting effectiveness. Genome Res 20: 1398-1410.

Calabrese JM, Seila AC, Yeo GW, Sharp PA. 2007. RNA sequence analysis defines Dicer's role in mouse embryonic stem cells. Proc Natl Acad Sci 104: 18097-18102.

Czech B, Malone CD, Zhou R, Stark A, Schlingeheyde C, Dus M, Perrimon N, Kellis M, Wohlschlegel JA, Sachidanandam $\mathrm{R}$, et al. 2008. An endogenous small interfering RNA pathway in Drosophila. Nature 453: 798-802.

Czech B, Zhou R, Erlich Y, Brennecke J, Binari R, Villalta C, Gordon A, Perrimon N, Hannon GJ. 2009. Hierarchical rules for Argonaute loading in Drosophila. Mol Cell 36: 445-456.

de Lencastre A, Pincus Z, Zhou K, Kato M, Lee SS, Slack FJ. 2010. MicroRNAs both promote and antagonize longevity in C. elegans. Curr Biol 20: 2159-2168.

Ekdahl Y, Farahani HS, Behm M, Lagergren J, Ohman M. 2012. A-to-I editing of microRNAs in the mammalian brain increases during development. Genome Res 22: 1477-1487. 
Fernandez-Valverde SL, Taft RJ, Mattick JS. 2010. Dynamic isomiR regulation in Drosophila development. RNA 16: 1881-1888.

Forstemann K, Horwich MD, Wee L, Tomari Y, Zamore PD. 2007. Drosophila microRNAs are sorted into functionally distinct argonaute complexes after production by dicer-1. Cell 130: 287-297.

Fukunaga R, Han BW, Hung JH, Xu J, Weng Z, Zamore PD. 2012. Dicer partner proteins tune the length of mature miRNAs in flies and mammals. Cell 151: 533-546.

Ghildiyal M, Seitz H, Horwich MD, Li C, Du T, Lee S, Xu J, Kittler EL, Zapp ML, Weng Z, et al. 2008. Endogenous siRNAs derived from transposons and mRNAs in Drosophila somatic cells. Science 320: 1077-1081.

Ghildiyal M, Xu J, Seitz H, Weng Z, Zamore PD. 2010. Sorting of Drosophila small silencing RNAs partitions microRNA* strands into the RNA interference pathway. RNA 16: 43-56.

Han BW, Hung JH, Weng Z, Zamore PD, Ameres SL. 2011. The 3'-to-5' exoribonuclease Nibbler shapes the 3' ends of microRNAs bound to Drosophila Argonaute1. Curr Biol 21: $1878-1887$.

Horwich MD, Li C, Matranga C, Vagin V, Farley G, Wang P, Zamore PD. 2007. The Drosophila RNA methyltransferase, DmHen1, modifies germline piRNAs and single-stranded siRNAs in RISC. Curr Biol 17: 1265-1272.

Hutvagner G, McLachlan J, Pasquinelli AE, Balint E, Tuschl T, Zamore PD. 2001. A cellular function for the RNA-interference enzyme Dicer in the maturation of the let-7 small temporal RNA. Science 293: 834-838.

Ibanez-Ventoso C, Yang M, Guo S, Robins H, Padgett RW, Driscoll M. 2006. Modulated microRNA expression during adult lifespan in Caenorhabditis elegans. Aging Cell 5: 235246.

Iki T, Yoshikawa $M$, Nishikiori $M$, Jaudal MC, MatsumotoYokoyama E, Mitsuhara I, Meshi T, Ishikawa M. 2010. In vitro assembly of plant RNA-induced silencing complexes facilitated by molecular chaperone HSP90. Mol Cell 39: 282291.

Iwasaki S, Kawamata T, Tomari Y. 2009. Drosophila argonaute1 and argonaute2 employ distinct mechanisms for translational repression. Mol Cell 34: 58-67.

Iwasaki S, Kobayashi M, Yoda M, Sakaguchi Y, Katsuma S, Suzuki T, Tomari Y. 2010. Hsc70/Hsp90 chaperone machinery mediates ATP-dependent RISC loading of small RNA duplexes. Mol Cell 39: 292-299.

Kamminga LM, Luteijn MJ, den Broeder MJ, Redl S, Kaaij LJ, Roovers EF, Ladurner P, Berezikov E, Ketting RF. 2010. Hen1 is required for oocyte development and piRNA stability in zebrafish. EMBO J 29: 3688-3700

Kato M, Chen X, Inukai S, Zhao H, Slack FJ. 2011. Ageassociated changes in expression of small, noncoding RNAs, including microRNAs, in C. elegans. RNA 17: 1804-1820.

Kawahara Y, Zinshteyn B, Sethupathy P, Iizasa H, Hatzigeorgiou AG, Nishikura K. 2007. Redirection of silencing targets by adenosine-to-inosine editing of miRNAs. Science 315: 11371140.

Kawamura Y, Saito K, Kin T, Ono Y, Asai K, Sunohara T, Okada TN, Siomi MC, Siomi H. 2008. Drosophila endogenous small RNAs bind to Argonaute 2 in somatic cells. Nature 453: 793-797.

Kenyon C. 2010. A pathway that links reproductive status to lifespan in Caenorhabditis elegans. Ann N Y Acad Sci 1204: 156-162.

Kirino Y, Mourelatos Z. 2007a. 2'-O-methyl modification in mouse piRNAs and its methylase. Nucleic Acids Symp Ser (Oxf) 51: 417-418.
Kirino Y, Mourelatos Z. 2007b. The mouse homolog of HEN1 is a potential methylase for Piwi-interacting RNAs. RNA 13: 1397-1401.

Kirino Y, Mourelatos Z. 2007c. Mouse Piwi-interacting RNAs are $2^{\prime}$-O-methylated at their $3^{\prime}$ termini. Nat Struct Mol Biol 14: $347-348$.

Kirino Y, Vourekas A, Khandros E, Mourelatos Z. 2011. Immunoprecipitation of piRNPs and directional, next generation sequencing of piRNAs. Methods Mol Biol 725: 281-293.

Kurth HM, Mochizuki K. 2009. 2'-O-methylation stabilizes Piwi-associated small RNAs and ensures DNA elimination in Tetrahymena. RNA 15: 675-685.

Landgraf P, Rusu M, Sheridan R, Sewer A, Iovino N, Aravin A, Pfeffer S, Rice A, Kamphorst AO, Landthaler M, et al. 2007. A mammalian microRNA expression atlas based on small RNA library sequencing. Cell 129: 1401-1414.

Lee HY, Doudna JA. 2012. TRBP alters human precursor microRNA processing in vitro. RNA 18: 2012-2019.

Lee RC, Feinbaum RL, Ambros V. 1993. The C. elegans heterochronic gene lin-4 encodes small RNAs with antisense complementarity to lin-14. Cell 75: 843-854.

Li J, Yang Z, Yu B, Liu J, Chen X. 2005. Methylation protects miRNAs and siRNAs from a 3 '-end uridylation activity in Arabidopsis. Curr Biol 15: 1501-1507.

Li LB, Yu Z, Teng X, Bonini NM. 2008. RNA toxicity is a component of ataxin-3 degeneration in Drosophila. Nature 453: $1107-1111$.

Li SC, Liao YL, Ho MR, Tsai KW, Lai CH, Lin WC. 2012. miRNA arm selection and isomiR distribution in gastric cancer. BMC Genomics 13: S13.

Li W, Prazak L, Chatterjee N, Gruninger S, Krug L, Theodorou D, Dubnau J. 2013. Activation of transposable elements during aging and neuronal decline in Drosophila. Nat Neurosci 16: 529-531.

Liu Q, Rand TA, Kalidas S, Du F, Kim HE, Smith DP, Wang X. 2003. R2D2, a bridge between the initiation and effector steps of the Drosophila RNAi pathway. Science 301: 1921-1925.

Liu N, Abe M, Sabin LR, Hendriks GJ, Naqvi AS, Yu Z, Cherry S, Bonini NM. 2011. The exoribonuclease Nibbler controls 3' end processing of microRNAs in Drosophila. Curr Biol 21: 1888-1893.

Liu N, Landreh M, Cao K, Abe M, Hendriks GJ, Kennerdell JR, Zhu Y, Wang LS, Bonini NM. 2012. The microRNA miR-34 modulates ageing and neurodegeneration in Drosophila. Nature 482: 519-523.

Llorens F, Hummel M, Pantano L, Pastor X, Vivancos A, Castillo E, Matllin H, Ferrer A, Ingham M, Noguera M, et al. 2013. Microarray and deep sequencing cross-platform analysis of the mirRNome and isomiR variation in response to epidermal growth factor. BMC Genomics 14: 371.

Marques JT, Kim K, Wu PH, Alleyne TM, Jafari N, Carthew RW. 2010. Loqs and R2D2 act sequentially in the siRNA pathway in Drosophila. Nat Struct Mol Biol 17: 24-30.

Marti E, Pantano L, Banez-Coronel M, Llorens F, MinonesMoyano E, Porta S, Sumoy L, Ferrer I, Estivill X. 2010. A myriad of miRNA variants in control and Huntington's disease brain regions detected by massively parallel sequencing. Nucleic Acids Res 38: 7219-7235.

Miyoshi T, Takeuchi A, Siomi H, Siomi MC. 2010. A direct role for Hsp90 in pre-RISC formation in Drosophila. Nat Struct Mol Biol 17: 1024-1026.

Neilsen CT, Goodall GJ, Bracken CP. 2012. IsomiRs-the overlooked repertoire in the dynamic microRNAome. Trends Genet 28: 544-549.

Nishida KM, Miyoshi K, Ogino A, Miyoshi T, Siomi H, Siomi MC. 2013. Roles of R2D2, a cytoplasmic D2 body compo- 
nent, in the endogenous siRNA pathway in Drosophila. Mol Cell 49: 680-691.

Nishikura K. 2010. Functions and regulation of RNA editing by ADAR deaminases. Annu Rev Biochem 79: 321-349.

Okamura K, Ishizuka A, Siomi H, Siomi MC. 2004. Distinct roles for Argonaute proteins in small RNA-directed RNA cleavage pathways. Genes Dev 18: 1655-1666.

Okamura K, Chung WJ, Ruby JG, Guo H, Bartel DP, Lai EC. 2008. The Drosophila hairpin RNA pathway generates endogenous short interfering RNAs. Nature 453: 803-806.

Okamura K, Liu N, Lai EC. 2009. Distinct mechanisms for microRNA strand selection by Drosophila Argonautes. Mol Cell 36: 431-444.

Okamura K, Robine N, Liu Y, Liu Q, Lai EC. 2011. R2D2 organizes small regulatory RNA pathways in Drosophila. Mol Cell Biol 31: 884-896.

Okamura K, Ladewig E, Zhou L, Lai EC. 2013. Functional small RNAs are generated from select miRNA hairpin loops in flies and mammals. Genes Dev 27: 778-792.

Pepper AS, Beerman RW, Bhogal B, Jongens TA. 2009. Argonaute2 suppresses Drosophila fragile X expression preventing neurogenesis and oogenesis defects. PLOS ONE 4: e7618.

Reinhart BJ, Slack FJ, Basson M, Pasquinelli AE, Bettinger JC, Rougvie AE, Horvitz HR, Ruvkun G. 2000. The 21-nucleotide let-7 RNA regulates developmental timing in Caenorhabditis elegans. Nature 403: 901-906.

Ren G, Chen X, Yu B. 2012. Uridylation of miRNAs by hen1 suppressor1 in Arabidopsis. Curr Biol 22: 695-700.

Ruby JG, Jan C, Player C, Axtell MJ, Lee W, Nusbaum C, Ge H, Bartel DP. 2006. Large-scale sequencing reveals 21U-RNAs and additional microRNAs and endogenous siRNAs in C. elegans. Cell 127: 1193-1207.

Seitz H, Ghildiyal M, Zamore PD. 2008. Argonaute loading improves the $5^{\prime}$ precision of both MicroRNAs and their miRNA $^{\star}$ strands in flies. Curr Biol 18: 147-151.

Smith-Vikos T, Slack FJ. 2012. MicroRNAs and their roles in aging. I Cell Sci 125: 7-17.

Taliaferro JM, Aspden JL, Bradley T, Marwha D, Blanchette M, Rio DC. 2013. Two new and distinct roles for Drosophila Argonaute-2 in the nucleus: Alternative pre-mRNA splicing and transcriptional repression. Genes Dev 27: 378-389.

Tomari Y, Matranga C, Haley B, Martinez N, Zamore PD. 2004. A protein sensor for siRNA asymmetry. Science 306: $1377-$ 1380.

Tomari Y, Du T, Zamore PD. 2007. Sorting of Drosophila small silencing RNAs. Cell 130: 299-308.

Vagin VV, Sigova A, Li C, Seitz H, Gvozdev V, Zamore PD. 2006. A distinct small RNA pathway silences selfish genetic elements in the germline. Science 313: 320-324.

Westholm JO, Ladewig E, Okamura K, Robine N, Lai EC. 2012. Common and distinct patterns of terminal modifications to mirtrons and canonical microRNAs. RNA 18: 177-192.

Wyman SK, Knouf EC, Parkin RK, Fritz BR, Lin DW, Dennis LM, Krouse MA, Webster PJ, Tewari M. 2011. Post-transcriptional generation of miRNA variants by multiple nucleotidyl transferases contributes to miRNA transcriptome complexity. Genome Res 21: 1450-1461.

Yu B, Yang Z, Li J, Minakhina S, Yang M, Padgett RW, Steward $\mathrm{R}$, Chen X. 2005. Methylation as a crucial step in plant microRNA biogenesis. Science 307: 932-935.

Zhao Y, Mo B, Chen X. 2012a. Mechanisms that impact microRNA stability in plants. RNA Biol 9: 1218-1223.

Zhao Y, Yu Y, Zhai J, Ramachandran V, Dinh TT, Meyers BC, Mo B, Chen X. 2012b. The Arabidopsis nucleotidyl transferase HESO1 uridylates unmethylated small RNAs to trigger their degradation. Curr Biol 22: 689-694. 


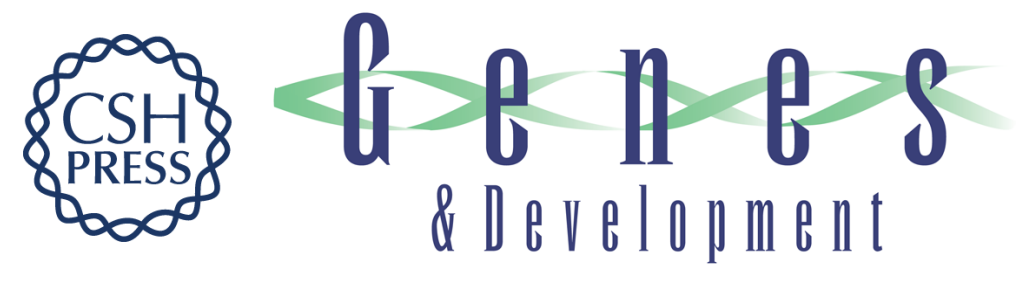

\section{Impact of age-associated increase in 2'-O-methylation of miRNAs on aging and neurodegeneration in Drosophila}

Masashi Abe, Ammar Naqvi, Gert-Jan Hendriks, et al.

Genes Dev. 2014, 28:

Access the most recent version at doi:10.1101/gad.226654.113

Supplemental http://genesdev.cshlp.org/content/suppl/2014/01/06/28.1.44.DC1
Material

References This article cites 70 articles, 28 of which can be accessed free at: http://genesdev.cshlp.org/content/28/1/44.full.html\#ref-list-1

Creative This article is distributed exclusively by Cold Spring Harbor Laboratory Press for the first Commons six months after the full-issue publication date (see

License http://genesdev.cshlp.org/site/misc/terms.xhtml). After six months, it is available under a Creative Commons License (Attribution-NonCommercial 3.0 Unported), as described at http://creativecommons.org/licenses/by-nc/3.0/.

Email Alerting Receive free email alerts when new articles cite this article - sign up in the box at the top Service right corner of the article or click here.

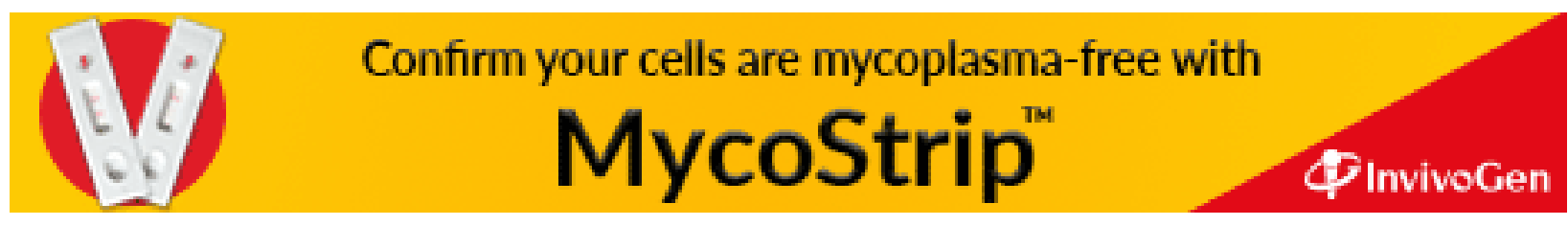

